\title{
Raymond Aron y José Ortega y Gasset: dos vidas paralelas en defensa del liberalismo
}

\section{Raymond Aron and José Ortega y Gasset: Two parallel lives in defense of liberalism}

Pedro Carlos González Cuevas

Universidad Nacional de Educación a Distancia (UNED), Madrid, España

pgonzalez@poli.uned.es

Resumen: Francia y España han sido dos sociedades muy diferentes. No obstante, hubieron de enfrentarse a una problemática análoga, sobre todo en los años treinta y en el periodo de la guerra fría, como era la de la crisis del sistema liberal. José Ortega y Gasset y Raymond Aron están unidos en su perspectiva de renovación del pensamiento liberal frente a las fuerzas políticas e intelectuales que lo pusieron en cuestión. Ambos defendieron una variedad de liberalismo que el sociólogo italiano Carlo Gambescia ha denominado "liberalismo árquico", basado en el historicismo y el realismo político.

Palabras Clave: liberalismo, democracia, fascismo, comunismo, historicismo, existencialismo, realismo político.

Abstract: France and Spain were two very different societies. Nevertheless, they had to face a similar problem especially in the 1930's and during the period of the cold war, as it was the crisis of the liberalism system. José Ortega y Gasset and Raymond Aron are united in their perspective of renewal of liberal thought in front of the political forces and intellectuals who put in question. Both defended a variety of liberalism that the italian sociologist Carlo Gambescia has been called "liberalism archic", based on the historicism and political realism.

Keywords: liberalism, democracy, fascism, comunism, historicism, existencialism, political realism. 


\section{LA CRISIS DEL LIBERALISMO}

Según señalaba José Ortega y Gasset, la trayectoria vital e intelectual del ser humano es consecuencia de tres factores fundamentales: la vocación, la circunstancia y el azar. La vocación es el tipo de hombre que la persona en cuestión pretende ser. Consiste en el más íntimo deseo del hombre, en su auténtico "yo". La circunstancia es el mundo de las cosas en derredor, las facilidades y dificultades con que la vida se encuentra para realizarse. La circunstancia es un ingrediente esencial en vida e incluye las facultades y aptitudes personales. El azar es un factor imprevisible que interfiere en ese sistema inteligible que forma la vocación y la circunstancia. "Escribir la biografía de un hombre - concluía Ortega y Gasset- es acertar en poner en ecuación esos tres valores" (Ortega y Gasset, 2006: 637).

Siguiendo este método, poco tenían que ver, al menos en apariencia, José Ortega y Gasset y Raymond Aron. José Ortega y Gasset nació en Madrid el 9 de mayo de 1883, en el seno de una familia de la alta burguesía dedicada al periodismo y a la política. Raymond Aron lo hizo en París el 14 de marzo de 1905, en el seno de una familia de clase media y ascendencia judía, aunque asimilada a las tradiciones francesas (Zamora Bonilla, 2002; Baverez, 1993). Así, pues, ambas individualidades pertenecen a generaciones muy distantes en el tiempo y a circunstancias nacionales no menos diversas. El español pertenecía a la generación de 1914; el francés, a la de 1936. Sin duda, las sociedades francesa y española eran profundamente diferentes. En España, el proceso de nacionalización de las masas había resultado, a lo largo del siglo XIX y comienzos del $\mathrm{xx}$, débil y desigual, como lo demostraba la emergencia de los nacionalismos periféricos catalán y vasco; mientras que Francia pasaba por ser el modelo por antonomasia de Estado centralizador y nacionalizador, el arquetipo, en fin, del triunfo de los valores jacobinos y nacionalistas. La sociedad española careció de un Estado fuerte capaz de penetrar en todos los rincones del país y desarrollar políticas económicas y culturales que permearan en el conjunto del territorio nacional, mientras que el francés se distinguió, en el ámbito europeo, por su eficacia a la hora de unificar la nación. El Estado español era confesionalmente católico, mientras que el francés se convirtió en el modelo de Estado laico, sobre todo desde 1905, cuando se consumó el proceso de separación Iglesia/Estado. El régimen español era una monarquía constitucional con amplios poderes del rey, mientras que el francés era una república parlamentaria. Desde 1898, España era un país carente de hinterland colonial, mientras que Francia disfrutaba de un extenso imperio en África y Asia. España fue neutral en la Gran Guerra, mientas que Francia fue una de las principales potencias beligerantes. Y, en fin, a lo largo del siglo XIX y comienzos del xx, la vida cultural española se caracterizó por la tensión entre una 
filosofía mediocre como el krausismo y filosofías anacrónicas como la neoescolástica y el tradicionalismo, mientras que las dos corrientes más fecundas del siglo, el positivismo y el idealismo, tuvieron una recepción tardía y marginal (Fernández Carvajal, 2000). En contraste, la sociedad francesa disfrutó de una mayor riqueza y pluralidad filosófica y cultural, a través del positivismo, el neoespiritualismo o el vitalismo bergsoniano (Winock, 1999 y 2001).

No obstante, lo que hace a sus personas y a sus respectivas obras paralelas y complementarias es la circunstancia transnacional de la crisis del liberalismo clásico, que arranca sobre todo del final de la Gran Guerra. Ya en las últimas décadas del siglo XIX, la ideología liberal comenzó a dar señales de un profundo desfallecimiento. Pero fue tras la Primera Guerra Mundial cuando se produjo el auténtico derrumbe del orden liberal, el auge del corporativismo y el ascenso del bolchevismo y de los regímenes fascista y nacional-socialista. En las sociedades de tradición liberal, como Inglaterra y Estados Unidos, tuvo lugar el ascenso del intervencionismo estatal y la construcción del llamado Estado del bienestar (Welfare State). En la Inglaterra de entreguerras, John Maynard Keynes, lord Beveridge y otros liberales revisionistas intentaron llegar a un punto de encuentro entre el viejo orden liberal-capitalista y las nuevas técnicas intervencionistas (Maier, 1988).

No era solo una crisis de carácter económico; el liberalismo se batía en retirada igualmente desde el punto de vista político e intelectual. Sufría una "crisis epistemológica" (Macintyre, 1994: 394) que solo podía superarse elaborando una serie de conceptos o nuevas síntesis de doctrinas e ideas, un nuevo marco de referencias. No en vano, Carl Schmitt, en los años veinte y treinta del pasado siglo, acusó al liberalismo de estar inspirado por un ethos que le impedía comprender el concepto de "enemigo"; y, en consecuencia, era incapaz de dotarse de una teoría realista del Estado y de la política. Inspirado en una fe ingenua en el progreso y en una visión optimista, en vez de realista, de la naturaleza humana, el liberalismo suponía, a juicio del constitucionalista alemán, una despolitización más o menos integral de la vida económica y social (Schmitt, 1991: 9899). A ello se unía las consecuencias de la "revolución intelectual" finisecular, auténtico corte epistemológico y estético frente a la concepción positivista decimonónica, en pos de nuevos horizontes culturales y científicos, como la microfísica, la teoría de la relatividad de Albert Einstein, el inconsciente de Sigmund Freud, el nihilismo de Nietzsche, la estética simbolista, etc. Frente a la razón positivista, lo irracional resurgía: la razón histórica y vital reprimida por el reduccionismo positivista se manifestaba e intentaba ajustar cuentas con la fría razón abstracta reinante. Esta revuelta contra el positivismo iba a dar lugar a la creación de nuevos fundamentos para el pensamiento europeo del siglo xx: el historicismo culturalista de Benedetto Croce, Ernst Troelsch y Fredrich 
Meinecke, el intuicionismo de Henri Bergson, el marxismo antipositivista de Georg Lukács, Karl Korsch o Walter Benjamin, el existencialismo de Martin Heidegger, o la nueva orientación sociológica de Max Weber (Schmitt, 1991: 98-99).

A pesar de la derrota de Alemania e Italia en la contienda, el impacto de la Segunda Guerra Mundial produjo por doquier una ampliación en el ámbito y la intensidad de la actividad estatal, incluso en los países de tradición liberal. En Inglaterra, el Plan Beveridge para la implantación de una economía mixta tuvo una clara influencia socialista, mientras que en Estados Unidos, su participación en la contienda afianzó las tendencias dirigistas e intervencionistas del New Deal. En Europa, el resultado de la guerra supuso el confinamiento de la Europa central y oriental en la esfera del sistema totalitario soviético, así como el ascenso al poder de los gobiernos socialistas en gran parte del resto del continente. Allí donde la opinión política no era franca y explícitamente socialista reinaba el consenso general de que el futuro se encontraba en el Estado interventor y una economía no de mercado libre, sino mixta y dirigida por el Estado. El éxito de la planificación de guerra convenció a la mayoría de los líderes políticos de que las misma técnicas podrían y deberían usarse para promover el pleno empleo en el contexto de un rápido crecimiento, $\mathrm{y}$ pareció otorgar la autoridad de la experiencia prácticas a las ideas económicas de Keynes, con su defensa de la capacidad del Estado para controlar la demanda en la economía de mercado a través de una intervención adecuada, aumentando el gasto público durante las recesiones, sobre todo para mantener el pleno empleo. No en vano, un economista y sociólogo como Joseph Schumpeter presagió el final del capitalismo y el ascenso de un nuevo sistema "socialista" (Schumpeter, 2015), si bien en su caso se trataba más bien de un sistema económico-social de corte burocrático-corporativo. Los años de posguerra asistieron, pues, a la consolidación del Estado del bienestar, cuyos orígenes se encontraban en la Alemania de Bismarck. Su objetivo era corregir por el sector público los efectos disfuncionales de la sociedad industrial competitiva, no solo por una exigencia ética, sino también por una necesidad histórica, dado que era preciso optar, primero, ante la presión de las clases trabajadoras, y luego ante el desafío comunista, entre la reforma y la revolución (García-Pelayo, 1977: 14).

En ese sentido, la trayectoria intelectual de José Ortega y Gasset y de Raymond Aron fue una respuesta a esa situación. Su proyecto político-intelectual tuvo como objetivo la reconstrucción del liberalismo. Ya desde sus primeros escritos Ortega y Gasset abogó por una renovación del pensamiento liberal que juzgaba hegemonizado, en España, por el conservadurismo ${ }^{1}$. No obstante, fue a partir de los años veinte cuando su

1 "La reforma liberal", Faro, 3-III-1908. 
proyecto adquirió unos perfiles más concretos y sistemáticos, a partir del método de la "razón histórica". El liberalismo, para Ortega, debía seguir el ejemplo metodológico de los liberales doctrinarios franceses, como François Guizot, viendo en "lo histórico" el "verdadero absoluto". "La historia es la realidad del hombre. No tiene otra. En ella se ha llegado a hacer tal y como es. Negar el pasado es absurdo e ilusorio, porque el pasado es 'lo natural del hombre que vuelve al galope'. El pasado no está ahí y no se ha tomado el trabajo de pasar porque lo neguemos, sino para que lo integremos (...) Los verdaderos derechos son los que absolutamente están ahí, porque han ido apareciendo y consolidándose en la historia, tales son las 'libertades', la legitimidad, la magistratura, las 'capacidades'. De alentar hoy hubieran reconocido el derecho a la huelga (no política) y el contrato colectivo" (Ortega y Gasset, 2004). En un sentido análogo se expresaba Raymond Aron. Su liberalismo no pretendía edificarse en "principios abstractos", sino, siguiendo el ejemplo de sus principales maestros, Montesquieu, Tocqueville, Pareto y Weber, en el análisis concreto y realista de las sociedades contemporáneas, buscando "las condiciones económicas y sociales que dan una oportunidad a la supervivencia del pluralismo, es decir, del liberalismo a la vez político e intelectual” (Aron, 2004: 233).

\section{LIBERALES IN PARTIBUS INFIDELIUM: AFINIDADES ELECTIVAS}

\section{Dos liberales árquicos}

¿Qué carácter tuvo el liberalismo defendido por Ortega y Aron? La pregunta no resulta ociosa, ya que el liberalismo es un movimiento intelectual y político plural en el que conviven diversas tradiciones e interpretaciones. En ese sentido, el sociólogo italiano Carlo Gambescia ha distinguido cuatro corrientes dentro del liberalismo contemporáneo: liberalismo micro-árquico, liberalismo an-anárquico, liberalismo macro-árquico y liberalismo árquico. El liberalismo micro-árquico se remonta a David Hume y Adam Smith, y tiene su desarrollo contemporáneo en la obra de Anton Menger, Ludwig von Mises, Friedrich von Hayek o Robert Nozick. Su fundamento es el "Estado mínimo", basado en la tesis de la identidad natural de los intereses económicos y sociales. El liberalismo an-árquico tiene su lejano predecesor en la obra de Bernard Mandenville, y adquiere continuidad en las obras de Murray Rothbard y Hans Hermann Hoppe. Se basa en el rechazo de la idea de Estado mínimo, sustituido por el libre ejercicio prepolítico de los derechos individuales. El liberalismo macro-árquico nace del utilitarismo de Jeremy Bentham, se desarrolla con John Stuart Mill y triunfa con la economía de John Maynard Keynes. Su proyecto es el Estado benefactor e interventor. Por último, el liberalismo 
árquico tiene sus orígenes en Edmund Burke y continúa en las obras de Alexis de Tocqueville, Vilfredo Pareto, Gaetano Mosca, Max Weber, Guglielmo Ferrero, Benedetto Croce, Isaiah Berlin, Julien Freund, etc. Sus fundamentos se encuentran en el historicismo, el pesimismo antropológico, el poder como elemento ineludible de la vida social y el realismo político. Su perspectiva contempla la sociedad como "un conjunto de órdenes concretos y particulares", y es consciente de la autonomía de lo político y del choque entre los distintos intereses económicos, sociales y políticos; en definitiva, una "compleja combinación de dolor, sentido de la realidad y tristeza" (Gambescia, 2015: 123-158).

En nuestra opinión, José Ortega y Gasset y Raymond Aron se encuentran unidos en la común perspectiva del liberalismo árquico, con algunos elementos del macro-árquico. Tanto en su trayectoria intelectual como personal son figuras afines. A pesar de las diferencias ya señaladas de generación y de la sociedad francesa y la española, no hay duda de que en una y en otra las actitudes y tendencias antiliberales eran muy profundas. A diferencia de otros pensadores liberales como Isaiah Berlin, Friedrich von Hayek o Karl Popper, insertos en el contexto social y político anglosajón, donde el liberalismo tenía grandes reservas, Ortega y Aron tuvieron que luchar con enemigos poderosos. En España, la Iglesia católica, la derecha tradicionalista o el socialismo marxista. En Francia, las tradiciones jacobinas, el tradicionalismo maurrasiano, el fascismo emergente, el comunismo y el socialismo. Tras la guerra civil española se instauró un régimen autoritario, confesional y corporativo paladinamente antiliberal, al que Ortega, finalmente, hubo de acomodarse, con grandes dificultades. En Francia, tras el final de la Guerra Mundial, Aron hubo de enfrentarse a una intelectualidad fascinada por el marxismo y el comunismo, cuyos representantes más carismáticos fueron Jean-Paul Sartre, Simone de Beauvoir, Maurice Merleau-Ponty, Louis Althusser, etc. En España, Ortega no tuvo, ni durante la II República ni durante el franquismo, adversarios de su talla, aunque fue muy criticado por los sectores más tradicionalistas del catolicismo y por socialistas como Luis Araquistáin. En aquel contexto adverso, Ortega y Aron fueron dos intelectuales comprometidos con su "circunstancia". No en vano, ambos se declararon "espectadores" de las situaciones políticas, sociales y culturales de sus respectivas naciones. Como diría Ortega, "la vida española nos obliga, queramos o no, a la acción política" (Ortega y Gasset, 2006: 159). Por su parte, Aron tituló significativamente uno de sus libros El espectador comprometido, es decir, "un hombre que observa, reflexiona y busca la mejor solución por el bien de los hombres" (Aron, 2004: 301). Ambos fueron "aristócratas en la plazuela", no solo escribieron libros e impartieron clase en sus respectivas cátedras universitarias, sino que colaboraron en la prensa diaria. Ortega, en El Imparcial, El Sol, La Nación, de Buenos Aires, Luz, etc.; Aron, en Le Figaro, L'Express, Preuves, etc. El español logró 
fundar su propio órgano cultural, Revista de Occidente. El francés, al final de su vida, influyó en la revista Commentaire. Desde el punto de vista religioso, fueron dos agnósticos respetuosos con las tradiciones religiosas (Ortega y Gasset, 1973: 77; Aron, 2007: 270-271). En el caso del español, puede ser conceptualizado como un "conservador heterodoxo", dada la preeminencia del factor religioso católico en la configuración ideológica del conjunto de las derechas españolas (González Cuevas, 2009: 69-131). Durante su juventud, ambos se sintieron influidos por el socialismo reformista. Ortega, por el socialismo ético de Hermann Cohen y Paul Natorp, y luego por Ferdinand Lassalle (Salmerón, 2014: 113-193). Aron se consideró pacifista y vagamente "socialista" sin ser marxista. En 1935, se afilió a SFIO y en 1936 votó por el Frente Popular, aunque criticó su programa económico (Baverez, 1993: 37; Sirinelli, 2005: 3).

\section{Formación alemana}

Tanto Ortega como Aron se mostraron insatisfechos del nivel cultural y político de sus respectivas sociedades. Ortega se dolía de la mediocridad del entorno cultural español. A su entender, la ciencia española era "un hecho personalísimo y no una acción social, o como quiera decirse lo que se ha llamado sinergia". "Ciencia bárbara, mística y errabunda ha sido siempre, y presumo que lo será, la ciencia española"2. De ahí que su formación intelectual tuviera una decisiva impronta francesa, a través de sus lecturas juveniles y maduras de Renan, Proust, Barrès, Taine, Guizot, Tocqueville, Durkheim, etc. (Ortega y Gasset, 1974: 26-36). A partir de los años treinta las obras del filósofo español comenzaron a ser traducidas al francés. Misión del bibliotecario lo fue en 1935 por la editorial Nourry. Y dos años después apareció La rebelión de las masas, en la editorial Stock, con un prólogo para franceses, donde el autor, exiliado entonces en Holanda tras el estallido de la guerra civil, alababa la perspectiva historicista de los liberales doctrinarios como François Guizot (Ortega y Gasset, 2004). Aron, en cambio, ignoró la cultura española. En su obra tan solo aparecen menciones a su amigo Salvador de Madariaga (Aron, 1968: 178; 1999: 142); y, como tendremos oportunidad de ver, a Ortega. Dada la situación de subdesarrollo económico y social y de inestabilidad política, Aron consideró la larga etapa de Franco como producto de "una necesidad trágica" (Aron, 2013: 180). Una opinión que, en el fondo, compartía Ortega cuando afirmaba, a finales de los años cuarenta, que los regímenes autoritarios "no eran realidades políticas engen-

\footnotetext{
2 “La ciencia romántica", El Imparcial, 4-VI-1906.
} 
dradas por el capricho o la intriga", sino "manifestaciones ineludibles del estado de guerra civil en que casi todos los países se hallan hoy" (Ortega y Gasset, 1985: 10 y 109).

Ambos coincidieron en su fascinación por la potencia cultural de Alemania. Desde su juventud, Ortega se sintió influido por Nietzsche. Y, a comienzos de 1905, viajó a la nación germana, matriculándose en la Universidad de Leipzig, donde asistió a las clases de Wundt y Mirsch. Luego pasó a Berlín, donde profundizó en la lectura de Kant, a través de Riehl y Simmel. Más importante fue su estancia posterior en Marburgo, donde se impregnó de la filosofía neokantiana de Hermann Cohen (Orringer, 1979). La influencia alemana continuó a través de Husserl, Dilthey, Scheler y Heidegger. Su pensamiento de madurez fue claramente heredero del historicismo alemán: la "razón histórica" o "razón vital", basada en una "radical historización" de la realidad humana (Ortega y Gasset, 2006: 45). Aron se vio igualmente tentado por Alemania. En sus memorias, se dolía del provincianismo cultural francés. Alemania fue, en ese sentido, su "destino" (Aron, 2013: 131). Trascendental fue su etapa en las universidades de Colonia y Berlín, donde se introdujo en el pensamiento filosófico y sociológico alemán. Estudió las obras de Dilthey, Rickert, Simmel y Weber (Aron, 1969). En Introducción a la filosofia de la historia, Aron puso a punto una concepción del papel de las ciencias sociales y de la relación entre el científico social y la política. Como Ortega, interpretó la realidad humana como esencialmente histórica. Inspirándose en Dilthey y en Weber, recuperó la tesis fundamental del historicismo alemán sobre las diferencias entre ciencias de la cultura y ciencias naturales, exaltando la necesidad de "comprensión" en las ciencias del hombre; desmontó las pretensiones científicas de las filosofías de la historia en su vertiente hegeliano-marxista, spengleriana y comtiana; y propuso una concepción de las tareas de la ciencia social. Dado que los éxitos históricos son indeterminados y dado que los actores históricos modifican el curso de la historia con sus decisiones y sus acciones, la tarea del científico social es la de favorecer las decisiones "razonables". Poniendo a disposición de los actores, estadistas o simples ciudadanos el conocimiento acumulado sobre los "determinismos parciales" - es decir, las regulaciones descubiertas en los comportamientos o en las interacciones sociales-, el científico social puede ayudar a los hombres de acción a tomar conocimiento de los vínculos en los cuales se podría encontrar su actuación y hacer buen uso, es decir, un uso razonable, de su libertad de decisión (Aron, 2012).

\section{Dos diagnósticos convergentes de una situación histórica}

A partir de ese método analizaron las realidades cotidianas de las sociedades europeas. Como liberales, tanto Ortega como Aron criticaron el fascismo y el nacional-socia- 
lismo, lo mismo que el comunismo. El filósofo español incidió más en el movimiento italiano, mientras que Aron, por obvias razones, lo hizo en el alemán. Ortega vio, en un primer momento, en el fascismo un "cariz enigmático", ya que aparecían en su seno los contenidos más opuestos: autoritarismo y rebelión; lucha contra la democracia y negativa a restaurar sistemas políticos pretéritos. Sus rasgos más nítidos eran, sin embargo, la violencia y la ilegitimidad, lo primero consecuencia de lo segundo. El fascismo era un movimiento político ilegítimo, porque no se preocupaba de dar fundamento a su práctica política, algo que era consecuencia de la crisis de las instituciones liberales que padecía Europa (Ortega y Gasset, 1972: 137). Posteriormente, desarrolló su crítica al fascismo como una de las diversas formas de "rebelión de las masas", consistente en el derrocamiento de las instituciones liberales y la exaltación de los valores plebeyos, en el que se radicalizaban todas y cada una de las patologías de la sociedad de masas: libre expansión de los deseos y radical ingratitud hacia las elites y hacia el pasado, conformismo, ausencia de un proyecto personal de vida, inercia mental, "acción directa", exaltación del Estado, etc. Además, el antiliberalismo fascista representaba una discontinuidad histórica y, por lo tanto, resultaba anacrónico: "El pasado tiene razón, la suya. Si no se le da esa que tiene, volverá a reclamarla, y de paso a imponer la que no tiene. El liberalismo tenía una razón, y esa hay que dársela por saeculam saeculorum" (Ortega y Gasset, 2004).

Aron caracterizó al nacional-socialismo como una "revolución antiproletaria", como una "revolución popular de derecha", cuya base social eran "las masas disponibles" movilizadas y unificadas por el partido, y que se rebelaban tanto frente a ciertas formas de capitalismo como de la "fatalidad de la proletarización". A sus ojos, el triunfo del nacional-socialismo era "una catástrofe para Europa, porque había reavivado una hostilidad casi religiosa entre los pueblos" (Aron, 2005: 39-41, 53). Los fascismos, a su juicio, no podían ser calificados de contrarrevolucionarios; eran auténticas revoluciones de derecha (Aron, 1979: 46). Como el comunismo, el nacional-socialismo era una "religión secular", producto de la dialéctica de la modernidad. Era la religión del "élan biológico", cuyo sujeto no era un ser racional, sino "un animal de presa" (Aron, 1996: 161). Se trataba igualmente de una consecuencia de las luchas entre las distintas generaciones, de los "jóvenes contra los viejos". El III Reich surgió, según Aron, de "la revuelta de un pueblo oprimido, nutrido de entusiasmo y de idealismo", que configuraba una Alemania "confiada en sí misma y en su porvenir" (Aron, 1993: 283-284). Este tipo de regímenes suponían un auténtico reto histórico en los países democrático-liberales, porque una buena parte de sus poblaciones deseaban otro tipo de sistema político (Aron, 2005: 68).

Tanto Ortega como Aron condenaron la democracia radical. Su enemigo fue Jean-Jacques Rousseau. El español lo contraponía a Mirabeau como político realista y defensor de la democracia frente a la revolución (Ortega y Gasset, 1974: 61); mientras que el 
francés recurría, en el mismo sentido, a Montesquieu (Aron, 2005: 344-358). Para uno y para otro, la democracia era aceptable siempre que estuviera templada por el liberalismo. En opinión de Ortega, la democracia liberal representaba "la más alta voluntad de convivencia" y el liberalismo era "la suprema generosidad: es el derecho que la mayoría otorga a las minorías y es, por tanto, el más noble grito que ha sonado en el planeta". Europa necesitaba conservar su esencial liberalismo, que era "la condición para superarlo" (Ortega y Gasset, 2004). Ahora bien, la democracia podía degenerar en la chabacanería y en el envilecimiento; y es que "la democracia exasperada y fuera de sí, la democracia en religión o en arte, la democracia en el pensamiento o en el gesto, la democracia en el corazón o en la costumbre es el más peligroso morbo que puede padecer una sociedad" (Ortega y Gasset, 2006: 271). Liberalismo y democracia eran dos respuestas a dos cuestiones de derecho político completamente distintas. Y es que mientras la democracia contestaba a la pregunta del sujeto político, haciendo recaer este sobre la colectividad de ciudadanos, el liberalismo contestaba a la pregunta sobre las limitaciones de dicho poder y sostiene que este no puede ser absoluto, por tener las personas derechos previos a toda interferencia del Estado. Y significativamente añadió: "Se puede ser liberal y nada demócrata o, viceversa, muy demócrata y nada liberal" (Ortega y Gasset, 1972: 31-33).

Por su parte, Aron se jactó de "despoetizar" y "desencantar" la democracia. A su entender, la democracia era "el único régimen que confiesa o, mejor aún, que proclama que la historia de los Estados está y debe estar escrita en prosa y no en verso" (Aron, 1979: 34). Para Aron, la democracia o régimen "constitucional-pluralista" se define sociológicamente como "la organización de la competencia pacífica con miras al ejercicio del poder", y no por la soberanía del pueblo, concepto que Aron calificaba de "malabarismo ideológico", ya que resultaba imposible definir qué era el pueblo. Ideas como la "voluntad general" de Rousseau podían llevar a la "dictadura del pueblo" o, mejor dicho, a la de "aquellos que dicen representarlo". La competencia electoral era la traducción posible de la idea de soberanía popular. Lo fundamental era, en ese sentido, el respeto a las minorías y la aceptación del compromiso de respetar la competencia pacífica (Aron, 1999: 99; 1965: 11, 124, 144-145).

Así, pues, tanto Ortega como Aron concibieron la democracia liberal como competición entre elites. Su concepción de la sociedad era la elitista, recibida de Gaetano Mosca y Vilfredo Pareto. Para Ortega, la sociedad es siempre "una unidad dinámica de dos factores: minorías y masas", es decir, entre individuos especialmente cualificados y personas no especialmente cualificadas" (Ortega y Gasset, 2004). En el caso de Aron, su concepción de las elites era más sociológica y política que moral y antropológica. "Un pequeño número de hombres, a menudo uno solo, que toma las decisiones que 
afectan a la suerte de todos" (Aron, 1969: 50; 1976: 209). Y es que la sociedad industrial se caracterizaba por la "antinomia entre la idea democrática y la estructura jerárquica de la actividad productiva, entre la igualdad de los ciudadanos y la desigualdad del poder de que dispone cada uno" (Aron, 1965: 198).

A diferencia de Aron, en la obra de Ortega existe una muy escasa reflexión sobre el tema económico. No obstante, el filósofo español fue muy consciente de la crisis en que se debatía el liberalismo económico: “(...) no es que seamos menos liberales; es que la vida pública se ha hecho demasiado compleja y difícil y obliga al Estado, quiera o no, a intervenir allí donde antes practicaba abstención, o, mejor dicho, fingía practicarla. Porque el viejo liberalismo, aunque brotaba de una aspiración generosa, tal vez la más generosa que se ha alzado nunca en la Historia concluía, por la forzosidad de los hechos, comportándose con grave hipocresía. Esta ha sido la causa de la decadencia padecida por la democracia liberal". A su entender, el estatismo era "el riesgo del Estado fuerte; pero no hemos acertado todavía los hombres a vivir sin riesgo" (Ortega y Gasset, 1973). En alguna ocasión hizo referencia a John Maynard Keynes como "persona aguda" (Ortega y Gasset, 2006: 567). Ya en 1918 había propugnado la creación de un "Parlamento industrial" y un "Ministerio de organización obrera" 3.

Aron no condenó el Estado benefactor; y apoyó las políticas keynesianas, en una versión moderada. En alguna ocasión se autodefinió como "keynesiano con alguna inclinación al liberalismo" (Aron, 1979: 10). En una polémica con el economista liberal Jacques Rueff, señaló que la Teoría General de Keynes representaba un progreso considerable para la ciencia económica, considerando a su antagonista como "pre-keynesiano" 4 . Aron creía que los efectos del Estado benefactor eclipsarían cualquier forma de apoyo a proyectos revolucionarios y difundirían entre las masas, sobre todo obreras, el escepticismo político, instauración de una economía mixta. Esto no es, como señalara Hayek, producto de una alteración inventada por los ideólogos socialistas, herederos del constructivismo de Saint-Simon y sus seguidores, sino que se inscribe en la propia lógica de los sistemas de democracia pluralista. La cuestión es entonces saber hasta donde debe llevar esta regulación para que no ponga en peligro las libertades fundamentales y la eficacia económica. En cualquier caso, Aron cree que el liberalismo económico sin trabas resulta incompatible con la democracia, es decir, con el sistema de competición política. Estaba convencido de que el régimen político competitivo conducía de manera casi fatal a un sistema de economía mixta; y que un liberalismo económico como lo

\footnotetext{
3 El Sol, 1-IV-1918, 24-IV-1918.

4 Critique n. ${ }^{\circ}$, noviembre 1946.
} 
concebía Hayek y otros liberales de su escuela conducía a la dictadura política. Existían, sin embargo, puntos de convergencia ocasionales entre Aron y Hayek. El sociólogo francés se apoyó en algunos planteamientos liberales clásicos hayekianos para mostrar a las democracias occidentales la necesidad de respetar exigencias esenciales de la tradición liberal, como la libertad de pensamiento y el respeto a los derechos individuales. Sin embargo, el liberalismo de Hayek reposaba, para Aron, sobre una base filosófica limitada e insatisfactoria. Y es que cuando Aron invocaba el fin de las ideologías designaba no solo al marxismo dogmático, sino también al "otro sistema global de interpretación", es decir, a "los liberales a lo Hayek" (Aron, 1999; 1966).

Mientras Ortega hizo referencia en 1923 al "ocaso de las revoluciones" (Ortega y Gasset, 2006: 619-638), Aron pronosticó el final de la "era ideológica" (Aron, 1979: 175). Ambos se mostraron muy escépticos respecto a la ideología del "progreso". Para Ortega y Gasset, tales planteamientos habían "cloromorfizado" al conjunto de las poblaciones occidentales y sus clases dirigentes. "La historia humana queda, así, deshuesada de todo dramatismo y reducida a un tranquilo viaje turístico, organizado por cualquiera agenda Cook de rasgo trascendente" (Ortega y Gasset, 2014: 38-39). Por su parte, Aron sostenía que en las sociedades industriales desarrolladas existía una contradicción insalvable entre la ideología "progresista", uno de cuyos componentes básicos era el igualitarismo, y el componente jerárquico que implicaba la división social del trabajo, al igual que la realidad oligárquica del sistema político demoliberal (Aron, 1969: 88).

Sin duda, fue La rebelión de las masas la obra de Ortega que suscitó un mayor interés en Aron. El pensador francés leyó el libro por vez primera en 1932 en una traducción alemana durante su estancia en Alemania como estudiante. Ya en su primera obra, hace referencia a la "rebelión de las masas" como fenómeno histórico-social, que "prueba al menos la posibilidad de otro régimen" (Aron, 2012: 412). En L'homme contre les tyrans, Aron recogía el concepto de civilización defendido por Ortega en la obra, como reducción progresiva de los hábitos violentos, para denunciar el "culto a la violencia como expresión más característica del retorno a la barbarie de algunos pueblos europeos del siglo xx" (Aron, 2005: 137). En sus reflexiones sobre la ciencia política, tomó nota sobre la tesis orteguiana según la cual la salud de la democracia liberal dependía del procedimiento electoral (Aron, 2006: 595). Aron analizó el concepto orteguiano de elite o minoría selecta, dictado, a su entender, "por una crítica aristocrática de la sociedad moderna" y que mostraba "un equívoco casi inevitable: los miembros de las clases superiores, salvo raras excepciones, adquieren solo ciertas cualidades propiamente intelectuales indispensables para ejercer ciertas funciones sociales". "Así, estas funciones son ejercidas efectivamente, o casi, por los miembros de las capas socialmente más elevadas. A ese respecto, creo - dirá Aron - que han tenido lugar menos cambios que 
los que sugiere el filósofo español". "La novedad es que políticamente los que gobiernan, tanto en democracia representativa como en regímenes de partido único, se adhieren a los hombres ordinarios y emplean un lenguaje o argumentos adaptados al bajo nivel supuesto de su público. El lenguaje comprensible a todos deviene en lenguaje de la propaganda, a menudo en los parlamentos, no de expertos, de funcionarios y de sabios. La aristocracia denuncia la caída de las elites al nivel de las masas, el demócrata la manipulación de las masas por las elites. Lo uno y lo otro muestran ciertos aspectos de la sociedad moderna, pero esto último me parece más próximo a lo esencial. Tanto en ciencia como en arte, las elites se alejan de las masas: para bien o para mal, se puede discutir indefinidamente. En todo caso, si las elites intelectuales hacen la corte al hombre de la calle o al hombre común no están molestos por la revuelta de los mediocres, sino por su propia mediocridad o por la demagogia”. En ese sentido, Aron contraponía Ortega a Jean-Paul Sartre (Aron, 1969: 121-122, 181).

En La rebelión de las masas, destacaba igualmente la reivindicación de la unidad de Europa. A juicio del filósofo español, Europa tenía que superar su actual situación de división y enfrentamiento entre Estados, si pretendía sobrevivir y dar respuesta al desafío bolchevique. La nación-estado, invento de la Edad Moderna, había cumplido su misión histórica y tenía que reformarse. La nación era una creación del Estado. Europa era algo más que el conjunto de sus naciones. Poseía una forma de ser propia que le confería un pasado histórico común, que todavía permanecía vivo y operante por debajo de los Estados que la conforman (Ortega y Gasset, 2004). En plena guerra fría, Aron se mostraba mucho más escéptico sobre las posibilidades de unificación del continente, sobre todo por la amenaza militar del comunismo y la debilidad de las sociedades europeas salidas del conflicto. Desconfiaba de la actitud de Gran Bretaña. Por ello, consideraba más factible la "comunidad atlántica" con Estados Unidos. Tampoco creía que los nacionalismos estuvieran en decadencia; y las diferencias culturales y estructurales entre las distintas sociedades eran muy importantes. Y concluía: "La idea europea es aún una idea vacía; no tiene ni la trascendencia de las ideologías mesiánicas, ni la inmanencia de las patrias materiales. Es una creación de intelectuales lo que revela a la vez su inoportunidad respecto a la razón y su débil resonancia en las masas”. En cualquier caso, pensaba que un eventual proyecto de unidad europea debería incluir a España (Aron, 1956: 401-428). Hasta el final de sus días tuvo una opinión muy pesimista con respecto a Europa, a la que consideraba "víctima de sí misma" (Aron, 1977: 249). A ese respecto, se preguntaba si se encontraba en entredicho o impotente, y si los europeos "habían perdido su patriotismo sin encontrar otro" (Aron, 2005: 216-218).

En cualquier caso, una de las frases de Ortega que llegó a fascinar a Aron era aquella de que ser de derechas o de izquierdas era una de las formas de ser imbécil. Algo que 
Aron veía en la Francia de los años ochenta, "agravada por la Constitución y el modo de escrutinio" (Aron, 2005: 817).

No deja de ser significativo que los enemigos intelectuales de Aron, Jean-Paul Sartre y Simone de Beauvoir (Aron, 1979), fueran objeto de críticas por parte de Ortega. El filósofo español opinó desdeñosamente sobre Sartre, quien, por aquellas fechas, ya había publicado obras de indudable impacto como La náusea o El ser y la nada. En opinión de Ortega, el existencialismo era, en aquellos momentos, una "epidémica moda en París". El filósofo español no creía que el compromiso fuese, en realidad, un acto especial o deliberado, sino que vivir era "estar ya comprometido, engagé, que es la palabra usada por los existencialistas". "Al lado de este radical y primario engagement o comprometimiento que es el simple vivir, todos los otros, secundarios y especiales, son superficiales, más aún frívolos, como se les ve más que con mirarles a la cara". Ortega pensaba que Sartre tenía "un gran talento"; pero "las cosas que dice haberse ahora (es decir, hace seis meses, porque le hemos visto variar con frecuencia) engagé son insulseces, son los más agusanados tópicos que andan hoy por la calle". "Y si un hombre de gran talento dice o hace una insulsez, la culpa no es suya, sino de la errónea doctrina en que está" (Ortega y Gasset, 1984: 277-278).

Más duro se mostró con la eterna compañera de Sartre, Simone de Beauvoir, autora de la influyente obra El segundo sexo, publicado en París en 1949. La filósofa analizaba, desde la perspectiva existencialista, la condición femenina, sometiendo a crítica el biologismo, el marxismo y el psicoanálisis. Entre los criticados se encontraba un amigo de Ortega, el doctor Gregorio Marañón, a quien acusaba de biologicista (Beauvoir, 2016: 102). La conclusión de Beauvoir era que la sexualidad no era, en el fondo, una característica natural o un hecho de la vida humana, sino una categoría construida a partir de la experiencia, cuyos orígenes eran históricos, sociales y culturales. En El hombre y la gente, Ortega sometió a crítica las tesis de Beauvoir, a la que calificó de "distinguida escritora de París, capital de la grafomanía". Sus tesis eran producto de la "manía igualitaria" que minimizaba "el hecho — uno de los hechos fundamentales en el destino humano - de la dualidad sexual". Para el filósofo español, no estaba clara la razón de "la incompatibilidad entre ser libre y consistir en estar referido a otro ser humano". "El libro de la señora Beauvoir, tan ubérrimo en páginas, nos deja la impresión de que la autora, afortunadamente, confunde las cosas y de este modo exhibe en su libro el carácter de confusión que nos asegura la autenticidad de su ser femenino. En cambio, creer, como de su escrito se desprende, que una mujer es más persona cuando no 'existe' preocupada por el hombre, sino ocupada en escribir un libro sobre le deuxième sexe, nos parece ya algo más que simple confusión". Y es que el destino de la mujer era "ser en vista del hombre". Como pensador historicista, Ortega creía que nuestro ser futuro 
emergía de nuestra libertad, pero esta libertad presuponía la elección de proyectos de comportamiento que solo podían formarse usando "del pasado - nuestro y ajenocomo de un material que nos inspire nuevas combinaciones". "El pasado — nuestro destino-, pues no influye sobre nosotros en forma impositiva y mecánica, sino como hilo conductor de nuestras inspiraciones. No quedamos inexorablemente inscritos en él, sino que nos lanza, en todo instante, a la libre creación de nuestro ser futuro". La negación del pasado era, pues, "la forma más estúpida de la vida humana aquella en que precisamente andamos más cerca de comportarnos con un automatismo casi físico". La mujer no era un producto de la naturaleza, sino "una invención de la historia como lo es el arte". La visión de la mujer como "sexo débil" era "fuente y origen del valor peculiar que la mujer posee referida al hombre". "Porque, gracias a ella, la mujer nos hace felices y es feliz ella misma, es feliz sintiéndose débil. En efecto, solo un ser inferior al varón puede afirmar radialmente el ser básico de esto — no sus talentos, ni sus triunfos, ni sus logros-, sin la condición elemental de la persona" (Ortega y Gasset, 2016: 160-167).

Raymond Aron se hizo eco en una de sus obras de esta crítica de Ortega a su compatriota y enemiga intelectual, calificándola de "graciosa" (joyeuse), que "no vacila en retomar, bajo una forma apenas modificada los temas clásicos". Y señalaba: "Esta filosofía va en sentido contrario de las ideas dominantes de nuestra época. No tiene oportunidad alguna de ser aceptada por todos los representantes del segundo sexo. La filosofía de Simone de Beauvoir tiene ventaja. A partir de datos biológicos que la ciencia no ha modificado todavía y de circunstancias sociales que no cesan de transformarse, las mujeres, dentro de ciertos límites sociales, escogen su modo de realización. ¿Por qué sostener o prever que todas las culturas adoptan los mismos modelos o reconocen el mismo valor a todos los modelos?" (Aron, 1969: 104-106).

Las obras de Ortega siguieron traduciéndose, aunque paulatinamente, a la lengua francesa. Velázquez en 1943, en la editorial Plon. Ideas y creencias, con un prólogo de Joan Estelrich, en 1945, en la editorial Stock. Un año después de su muerte el Bulletin de l'Institut Française en Espagne publicó un "Hommage à Ortega y Gasset" 5 . El Espectador, en Plon, en 1958. Cuatro años antes se tradujo la obra de Julián Marías, discípulo por antonomasia de Ortega, Philosophes espagnols de nôtre temps, en Aubier-Montagne. El hispanista Alain Guy publicó en Espasa-Calpe, en 1968, Ortega y Gasset, crítico de Aristóteles: la ambigüedad del pensar peripatético juzgada por el raciovitalismo. El ensayista y escritor Albert Camus, admirador del filósofo español, pretendió, desde su puesto de consejero de la editorial Gallimard, promocionar y comenzar a pu-

\footnotetext{
5 “Hommage à Ortega y Gasset", Bulletin de l'Institut Française en Espagne n. . 90, abril de 1956.
} 
blicar sus obras en francés, pero su pronta muerte hizo olvidar el proyecto. La evolución de la teoría deductiva y La idea del principio en Leibniz lo serían en 1970, precisamente en Gallimard.

\section{Recepciones cruzadas}

El sociólogo galo conoció personalmente al filósofo español en París, en 1951, a través del historiador Luis Díez del Corral, el célebre autor de El liberalismo doctrinario, devoto, como Aron, de la figura de Alexis de Tocqueville. Hablaron del mundo hispanoamericano y de la teoría orteguiana de la mujer criolla ${ }^{6}$.

Muchos años después, tanto la revista Commentaire como el diario español $A B C$ publicaron un ensayo inédito de Aron dedicado a La rebelión de las masas. Se trataba del texto de una conferencia que el pensador galo había proyectado pronunciar en mayo de 1983 en el Instituto Ortega y Gasset de Madrid, con motivo del centenario del nacimiento del filósofo español, y que la muerte le impidió realizar. Aron no dudaba en calificar al filósofo español de "maestro del pensamiento"; y lo comparaba con Benedetto Croce. En la conferencia, Aron confesaba haber leído el libro por vez primera en 1932, "en una traducción alemana durante el ascenso del movimiento hitleriano". Para Aron, Ortega era un pensador "antirrevolucionario"; porque juzgaba "la idea de revolución, de la transformación total de la sociedad como una iniciativa falsa, rechazada por la experiencia histórica de los últimos siglos del pasado europeo". "Si Sartre se ha equivocado tan a menudo cuando escribía sobre política es porque jamás se curó de su revolucionarismo". Y es que esa actitud mental o moral consistía "en un desconocimiento de los deseos imperativos de la 'razón histórica': la continuidad y el cambio". Como antirrevolucionario, Ortega permaneció fiel al liberalismo y manifestó su admiración por los doctrinarios franceses, al igual que su adhesión a las instituciones representativas. De esta forma, el pensador español se mostró como un "filósofo civilizado". No obstante, Aron criticó su valoración despectiva tanto de la Rusia soviética como de Estados Unidos. Y es que Rusia se había identificado con una ideología como el marxismo que "no había perdido su capacidad de expansión, aunque en Europa occidental parece destinada a una decadencia irreversible"; mientras que Estados Unidos, lejos de ser una sociedad meramente utilitaria, había alcanzado en los ámbitos de la ciencia pura "un lugar eminente". Sin embargo, la idea más vigente defendida por Ortega era la de su proyecto de

\footnotetext{
${ }^{6}$ Carmen Iglesias, "Reencarnación del pensamiento socrático", ABC, 17-X-1993.
} 
unidad europea, que se configuraba como la alternativa de "la causa de una Europa que se cree decadente" 7 .

Gracias a la conferencia de Aron, el pensamiento de Ortega logró una mayor difusión en la sociedad francesa como representante del liberalismo europeo. En la Histoire de la litterature espagnole, dirigida por Jean Canavaggio, Ortega aparece como líder del pensamiento español y gran teórico del liberalismo europeo con Tocqueville y Aron. A partir de finales de los años ochenta, se tradujeron al francés ¿Qué es filosofia?, Lecciones de metafisica, Velázquez, Goya, Escritos sobre el amor, etc (Fonck, 2008). Sin embargo, las traducciones han continuado en la editorial Klincksieck y en 1988 proyectó la publicación de sus Oeuvres Complètes. Por esas mismas fechas, se publicó, en Distance, sus Escritos sobre el amor. Aurora de la razón histórica y Qué es filosofía, Lecciones de metafisica, en 1988. La rebelión de las masas, en Le Labyrinthe. Meditations sur la chasse, en 2000, en Septenton. Meditations sur la technique, en 2017. L'Histoire comme système, en 2016, en Éditions Allia. Misère et splendeur de la traduction, en 2013, por Les Belles Llettres, etc., etc. En 1996, Bernard Milhou publicó en Éditions Universitaires du Sud Prolegomènes a une esthétique de l'existence: Ortega y Gasset entre Bergson et Heidegger. Y Christian Pierre e Yves Lorvellec en 2001, Ortega y Gasset et l'exigence de verité, en la editorial Michalon.

Igualmente, el pensamiento de Aron comenzó a tener buena acogida en la sociedad española a finales de los años sesenta (González Cuevas, 2016: 183-215). La recepción del pensamiento aroniano en España se vio bloqueada, en un principio, tanto a nivel filosófico como de teoría social, por la realidad de un régimen político autoritario, hostil, sobre todo en sus primeros momentos, al liberalismo. No obstante, a finales de los años cincuenta Aron comenzó a traducirse al español. En 1958, Un siglo de guerra total, por la Editorial Hispano-Europea. Dimensiones de la conciencia histórica, por Tecnos en 1963. Seix Barral publicó entre 1968 y 1971 Dieciocho lecciones sobre la sociedad industrial, La lucha de clases y Democracia y totalitarismo. Alianza, Ensayo sobre las libertades y La república imperial. La revolución estudiantil, en Desclée de Browner. La era tecnológica en Alfa de Motevideo. Incluso publicó un artículo, "La ideología base esencial de la acción", en el volumen colectivo Las ideologías y sus aplicaciones en el siglo $X X$, editado por el Instituto de Estudios Políticos. Con posterioridad, fue traducida Paz y guerra entre las naciones y Memorias por Alianza. En Venezuela, la

7 ABC Literario, 6 y 13-II-1988. "Ortega y Gasset et la 'revolte des masses"”, en Commentaire n. ${ }^{\circ} 40$, 1987/4, pp. 733-740. En el mismo número de la revista aparecía un artículo de François-Michel Pasquet, “En l'honneur d'un vivant: Ortega y Gasset (1883-1945), en ibidem, pp. 741-749. 
editorial Monte Ávila publicó De una sagrada familia a otra. Ensayo sobre los marxismos imaginarios, Historia y dialéctica de la violencia y Las desilusiones del progreso.

Además, Aron tuvo, como hemos señalado, alguna relación con intelectuales españoles. Fue el caso de Luis Díez del Corral y José Antonio Maravall, dos historiadores muy relacionados con Ortega. El primero siempre tuvo una buena opinión de la obra y de la personalidad del intelectual francés: "Las dotes de observación, de análisis, de tolerancia y de comprensión quedaban bien manifiestas día tras día (...). Conocedor de toda clase de problemas, dotado para el análisis y para la síntesis, sus juicios expresados tanto a través del artículo como de libros eran universalmente respetados" (Díez del Corral, 1963). Díez del Corral y Aron coincidieron, sobre todo, en su interés y admiración por la figura y la obra de Alexis de Tocqueville. Como Aron, el historiador español creía que el autor de La democracia en América era, "junto a Carlos Marx, el pensador decimonono que mayor atención despierta en nuestros días entre los historiadores de las ideas políticas". En sus estudios tocquevillianos, Díez del Corral se hacía eco de las interpretaciones aronianas sobre el pensador normando; y recogía su teoría de la sociedad industrial, que "no impone ni el partido único, de la que la Unión Soviética ofrece el modelo ni el pluralismo de partidos e ideologías del que se enorgullecen en Occidente". Igualmente incidía en su "serio conocimiento" tanto de la obra de Tocqueville como de la de Marx. Para Díez del Corral, Aron era representante y continuador de la corriente intelectual "típicamente francesa" que arrancaba de Jean Bodin; llegaba a Montesquieu y culminaba en Tocqueville y en el propio Aron: "Es una corriente que puede variar su curso, pues al perseguir la comprensión de la realidad no desde unos postulados de escuela consagrada, sino, aunque utilice sus categorías y su estilo clasificatorio, con afán de entender la realidad actual tal como es, ha de adaptar dichas categorías, actualizándolas y revitalizándolas" (Díez del Corral, 1989). La relación de Aron con Díez del Corral continuó. Ambos intervinieron en el Coloquio de Rheinfelden en 1960; contactaron durante dos breves viajes que Aron hizo a España; y en la Comisión Nacional para la Edición de las Obras de Tocqueville ${ }^{8}$.

José Antonio Maravall fue nombrado director del Colegio de España en febrero de 1949. A lo largo de su estancia en París se familiarizó con la obra de los miembros de la escuela de Annales, en particular Lucien Febvre y Fernand Braudel. Allí coincidió con Díez del Corral, a la sazón consejero cultural del Ministerio de Asuntos Exteriores, quien organizó una cena con Raymond Aron. Según Díez del Corral, no simpatizaron: "Pronto la dejadez en la conversación y un cierto aire de aburrimiento delataron que el

\footnotetext{
${ }^{8}$ Carmen Iglesias, "Reencarnación del pensamiento socrático", ABC, 17-X-1993.
} 
contertulio no le interesaba demasiado a Maravall"9. No obstante, Maravall leyó su obra Introducción a la filosofía de la historia, que influyó en la gestación de su célebre Teoría del saber histórico, con su insistencia en la primacía de las teorías sobre los hechos (Maravall, 1958: 44; 88).

En 1973, el sociólogo Luis Rodríguez Zúñiga publicó su tesis doctoral Raymond Aron y la sociedad industrial. Años después, Montserrat Gimbernat, El pensament sociologic de Raymond Aron, en 1988. Yolanda Casado, El pensamiento histórico y político de Raymond Aron. Y Pedro Gago Guerrero, La concepción de la política internacional en Raymond Aron.

No son solo sociólogos y politólogos los que han revalorizado en nuestro país la obra de Raymond Aron; es buena parte de la derecha intelectual española la que se ha vuelto, en cierto modo, "aroniana". Lo que no es, desde luego, una mala opción. Desde su muerte se han seguido editando y reeditando en español obras del pensador galo: Los últimos años del siglo y Ensayos sociológicos en Espasa-Calpe; Las etapas del pensamiento sociológico, en Tecnos; Ensayo sobre las libertades, en Alianza; Pensar la guerra, en Ediciones del Ministerio de Defensa; El marxismo de Marx, en Siglo XXI. El opio de los intelectuales y Memorias, por RBA. En Página Indómita: Dimensiones de la conciencia histórica, Democracia y totalitarismo e Introducción a la filosofía política. El interés por su obra ha ido en aumento. A los diez años de su muerte, el diario $A B C$ recordaba su figura y su obra como "un gigantesco intento de liberar a la cultura francesa y buena parte de la cultura europea de la tiranía de la ceguera, la ignorancia y la frivolidad terrorista". La historiadora Carmen Iglesias — discípula de Díez del Corral y de Maravall— lo consideraba "la reencarnación del pensamiento socrático": "Como Sócrates, Aron ha sido constantemente el tábano que no ha cesado de aguijonear a sus contemporáneos; les ha impedido que "descansasen" en sus seguridades; ha destrozado sus tópicos..."10. El escritor peruano-español Mario Vargas Llosa, miembro del Consejo de Redacción de la revista aroniana Commentaire, considera tanto al español como al francés sus maestros en el campo del pensamiento político liberal (Vargas Llosa, 2018: 69-98, 205-239). Significativamente, en 2005, en conmemoración de su centenario, la Fundación para el Análisis y los Estudios Sociales (FAES) publicó, bajo la dirección de José María Lasalle, un volumen colectivo titulado Raymond Aron: un liberal resistente, en cuyas páginas colaboraron Jean-François Revel, Nicolás Baverez, José Manuel Romay, Alejandro Muñoz

9 Luis Díez del Corral, “Recuerdos de José Antonio Maravall”, en Cuadernos Hispanoamericanos n. ${ }^{\circ}$ 477-478, marzo-abril 1990.

${ }^{10}$ Carmen Iglesias, "Reencarnación del pensamiento socrático", $A B C, 17-\mathrm{X}-1993$. 
Alonso, Alexandro Campi, Enrique Aguilar, Pedro Fernández Gago, Felipe Sahagún, Julián García Vargas, Jerónimo Molina Cano y Agapito Maestre.

\section{BIBLIOGRAFÍA}

Aron, R. (1938) (2012). La philosophie critique de l'histoire. Essai sur les limites de la objetivité historique. Gallimard. París.

- (1938) (1969). La philosophie crique de l'histoire. Essai sur une theorie allemande de l'histoire. J. Vrin.

- (1958). Un siglo de guerra total. Editorial Hispano-Europea. Barcelona

- (1966). Ensayo sobre las libertades. Alianza. Madrid.

- (1968). Democracia y totalitarismo. Seix Barral. Barcelona.

- (1969). Les desilusions du progres. Essai sur la dialectique de la modernité. Perrin. París.

- (1976). Las etapas del pensamiento sociológico. Siglo XX. Buenos Aires,

- (1977). En defensa de la libertad y de la Europa liberal. Argos Vergara. Barcelona,

- (1955). (1979) -El opio de los intelectuales. Siglo XX. Buenos Aires.

- (1979) Estudio introductorio a El político y el cientifico de Max Weber. Alianza. Madrid.

- (1993). Machiavel et les tyranies modernes. Falois. París.

- (1996). Une histoire du XX siècle. Perrin. París.

- (1999). Introducción a la filosofía política. Gedisa. Barcelona.

- (2004). Le spectateur engagé. Falois. París.

- (2005). Pênser la liberté, pênser la democratie. Gallimard. París.

- (2005). De Giscard à Mitterrand. Falois. París.

- (2006). Les societées modernes. PUF. París

- (2007). Essais sur la condition juive contemporaine. Falois. París.

- (2013). Memorias. Medio siglo de reflexión politica). RBA. Barcelona.

Baverez, N. (1993). Raymond Aron. Un moraliste au tempos des ideologies. Flammarion. París.

Beauvoir, S. de (1949) (2016). El segundo sexo. Cátedra. Valencia.

Diez del Corral, L. (1966). La mentalidad politica de Tocqueville con especial referencia a Pascal. Real Academia de Ciencias Morales y Políticas. Madrid.

- (1989). El pensamiento político de Tocqueville). Alianza. Madrid.

Fernández Carvajal, R. (2000). El pensamiento español del siglo XIX. Nausicaa. Murcia. 
Fonck, B. (2008). “La recepción de Ortega en Francia”, en Reviste de Occidente n. ' 324, mayo de.

Gambescia, C. (2015). Liberalismo triste. Un recorrido de Burke a Berlin. Encuentro. Madrid.

García Pelayo, M. (1977). Las transformaciones del Estado. Alianza. Madrid.

González Cuevas, P. C. (2009). Conservadurismo heterodoxo. Tres vías ante las derechas españolas: Maurice Barrès, José Ortega y Gasset y Gonzalo Fernández de la Mora. Biblioteca Nueva. Madrid,

- (2016). "Raymond Aron y España", en Estudios revisionistas sobre las derechas españolas. Universidad de Salamanca.

Macintyre, A. (1994). Justicia y racionalidad. Eiunsa. Barcelona.

Maier, C. S. (1988). La reconstrucción de la Europa burguesa Ministerio de Trabajo y Seguridad Social. Madrid.

Maravall, J. A- (1958). Teoría del saber histórico. Revista de Occidente. Madrid.

Orringer, N. (1979). Ortega y las fuentes germánicas. Gredos. Madrid.

Ortega y Gasset, J. (1930) (2004). "La rebelión de las masas", en Obras Completas. Tomo IV. Taurus/Fundación Ortega y Gasset. Madrid.

- (1972). "Sobre el fascismo", en El Espectador Tomo V-VI. Revista de Occidente. Madrid.

- (1973). Rectificación de la República. Revista de Occidente. Madrid.

- (1974). Mocedades. Espasa-Calpe. Madrid.

- (1974). Mirabeau o el político. Contreras o el aventurero. Revista de Occidente. Madrid.

- (1985). Europa y la idea de Nación. Alianza. Madrid.

- (1984). Una interpretación de la Historia Universal. Alianza/Revista de Occidente. Madrid.

— (2004). “El espectador” (1917-1934)” en Obras Completas. Tomo II. Taurus/Fundación Ortega y Gasset. Madrid.

- (2006). "La Historia como sistema", en Obras Completas. Tomo VI. Taurus/Fundación Ortega y Gasset. Madrid.

- (2014). Ensimismamiento y alteración. Meditaciones de la técnica y otros ensayos (1933). Alianza. Madrid.

- (2016). El hombre y la gente. Biblioteca Nueva. Madrid.

Salmerón, F. (2016). "El socialismo del joven Ortega", en José Ortega y Gasse Fondo de Cultura Económica. México.

Schmitt, C. (1932) (1991). El concepto de lo politico. Alianza. Madrid. 
Schumpeter, J. A. (2015)., Capitalismo, socialismo y democracia. Página Indómita. Barcelona

Sirinelli, J. F. (2005). "Raymond Aron avant Raymond Aron", en Comprendre XX siècle français . Gallimard. París.

Stuart Hughes, H. (1972). Conciencia y sociedad. La reorientación del pensamiento social europeo. Aguilar. Madrid.

Vargas Llosa, M. (2018). La llamada de la tribu. Alfaguara. Madrid.

Winock, M. (2001). Les voix de la liberté: les ecrivains engagés au XIX siècle. Seuil. París.

- (1999). Le siècle des intelectuels. Seuil. París.

Zamora, J. (2002). Ortega y Gasset. Plaza y Janés. Barcelona. 